\title{
Sarcoidosis is a Th1/Th17 multisystem disorder
}

\author{
Monica Facco, ${ }^{1,2}$ Anna Cabrelle, ${ }^{2}$ Antonella Teramo, ${ }^{1,2}$ Valeria Olivieri, ${ }^{1,2}$ \\ Marianna Gnoato, ${ }^{2}$ Sara Teolato, ${ }^{1}$ Elisa Ave, ${ }^{1,2}$ Cristina Gattazzo, ${ }^{1,2}$ Gian Paolo Fadini, ${ }^{3}$ \\ Fiorella Calabrese, ${ }^{4}$ Gianpietro Semenzato, ${ }^{1,2}$ Carlo Agostini ${ }^{1,2}$
}

\begin{abstract}
- Additional methods are published online only. To view these files please visit the journal online (http://thorax.bmj. com).

${ }^{1}$ Department of Clinical and Experimental Medicine, Hematology-Immunology Section, Padua University School of Medicine, Padova Italy

${ }^{2}$ Venetian Institute of Molecular Medicine, Padua University School of Medicine, Padova, Italy

${ }^{3}$ Department of Clinical and Experimental Medicine,

Metabolic Diseases, Padua University School of Medicine, Padova, Italy

${ }^{4}$ Department of Diagnostic Medical Sciences and Special Therapies, Padua University School of Medicine, Padova, Italy
\end{abstract}

\section{Correspondence to}

Carlo Agostini, Padua University School of Medicine, Department of Clinical and Experimental Medicine, Hematology and Clinical Immunology Section, Via Giustiniani 2, 35128 Padova, Italy; carlo.agostini@unipd.it

Received 9 April 2010 Accepted 29 October 2010

Published Online First

7 December 2010

\section{ABSTRACT}

Background and aims Sarcoidosis is characterised by a compartmentalisation of $\mathrm{CD}^{+}{ }^{+} \mathrm{T}$ helper 1 (Th1) lymphocytes and activated macrophages in involved organs, including the lung. Recently, Th17 effector CD4 ${ }^{+}$ $T$ cells have been claimed to be involved in the pathogenesis of granuloma formation. The objective of this study was to investigate the involvement of Th17 cells in the pathogenesis of sarcoidosis.

Methods Peripheral and pulmonary Th17 cells were evaluated by flow cytometry, real-time PCR,

immunohistochemistry analyses and functional assays in patients with sarcoidosis in different phases of the disease and in control subjects.

Results Th17 cells were detected both in the peripheral blood $\left(4.72 \pm 2.27 \%\right.$ of $\mathrm{CD}^{+} \mathrm{T}$ cells) and in the bronchoalveolar lavage (BAL) $\left(8.81 \pm 2.25 \%\right.$ of $\mathrm{CD}^{+}{ }^{+}$ lymphocytes) of patients with sarcoidosis and $T$ cell alveolitis. Immunohistochemical analysis of lung and lymph node specimens showed that interleukin 17 $(\mathrm{IL}-17)^{+} / \mathrm{CD}^{+} \mathrm{T}$ cells infiltrate sarcoid tissues surrounding the central core of the granuloma. IL-17 was expressed by macrophages infiltrating sarcoid tissue and/or forming the granuloma core $17.88 \pm 2.40 \%$ of alveolar macrophages). Analysis of some lung specimens highlighted the persistence of $\mathrm{IL}-17^{+} / \mathrm{CD} 4^{+} \mathrm{T}$ cells in relapsed patients and their absence in the recovered cases. Migratory assays demonstrated the ability of the Th17 cell to respond to the chemotactic stimulus CCL20 - that is, the CCR6 ligand (74.8 \pm 8.5 vs $7.6 \pm 2.8$ migrating BAL lymphocytes/high-powered field, with and without CCL20, respectively).

Conclusions Th17 cells participate in the alveolitic/ granuloma phase and also to the progression towards the fibrotic phase of the disease. The recruitment of this cell subset may be driven by CCL20 chemokine.

\section{INTRODUCTION}

Sarcoidosis is a multisystemic granulomatous disease of unknown aetiology characterised by a compartmentalisation of CD4 ${ }^{+} \mathrm{T}$ helper 1 (Th1) lymphocytes and activated monocyte/macrophages in involved organs, including the lung, lymph nodes and skin. ${ }^{1}$ In $\sim 60 \%$ of patients the disease spontaneously resolves, but in some subjects the persistence of the antigenic stimulus favours a chronic inflammatory state, granuloma lung formation and, in some cases, an evolution towards fibrosis. ${ }^{2}$ A complex network of cytokines and chemokines orchestrates the pathogenesis of sarcoidosis: early phases are characterised by a local overproduction of Th1 cytokines, such as interleukin 2 (IL-2) and interferon $\gamma$ (IFN $\gamma$ ), ${ }^{3}$ associated with the high expression of macrophage-derived molecules such as IL-15, ${ }^{4}$ CXCL10, ${ }^{5}$ CXCL16, $\mathrm{CCL}^{7}$ and $\mathrm{CCL} 20{ }^{8}$

Th17, a new $\mathrm{CD}^{+}$effector T cell population, has been recently described. ${ }^{9}$ Initially identified for its ability to produce IL-17A, IL-17F and IL-22, it is now known that human Th17 cells develop in response to IL-23 and IL-1 $\beta$. These cells espress CD4, CD45RO, CCR6 (actually, the unique known receptor of the chemokine CCL20), CCR4 and the subunit IL-23R (the specific receptor for the p19 chain of IL-23). In addition, Th17 lymphocytes express a specific master transcription factor known as retinoic acid-related orphan receptor $(\mathrm{ROR}) \gamma \mathrm{t}^{10}{ }^{11}$ and release an array of cytokines, including proinflammatory molecules such as tumour necrosis factor $\alpha$ (TNF $\alpha$ ) and IL-6. ${ }^{12}$ Recent studies have highlighted the effector role of Th17 cells in pathological conditions, including autoimmunity and inflammation. In particular, the Th17 subset has been linked to Th1 chronic inflammatory diseases, such as psoriasis and inflammatory bowel diseases, and also lung fibrosis. ${ }^{13-15}$

Herein, we investigate the hypothesis that Th17 cells are involved in the pathogenesis of sarcoidosis. Forty patients were stratified in different phases of the disease and compared with healty controls. Our results clearly demonstrate that Th17 cells infiltrate the sarcoid lung and that CCL20 chemokine contributes to the recruitment of these proinflammatory cells from the blood into the lung.

\section{MATERIALS AND METHODS Study population}

Forty patients with sarcoidosis were analysed. In all cases, the diagnosis was made from a biopsy obtained either from the lungs or from lymph nodes and showing non-caseating epithelioid granulomas with no evidence of inorganic material known to cause granulomatous diseases. Thirty-six patients underwent bronchoalveolar lavage (BAL) fluid analysis. In particular, 25 patients with sarcoidosis presenting with an episode of pulmonary involvement were evaluated at the onset of the disease. They were defined as having a high intensity alveolitis (ie, the active form of the disease) on the basis of the following characteristics: lymphocytic alveolitis $\left(>30 \times 10^{6}\right.$ lymphocytes/L) and lung CD4 to $\mathrm{CD} 8$ ratio $>4.0$. The assessment of disease activity included BAL, clinical features, chest radiograph, lung function tests, high-resolution CT and routine blood studies. BAL samples were also obtained from 11 patients with previously diagnosed pulmonary sarcoidosis who repeated BAL fluid analysis during their follow-up period. These patients had normal lung function, normal BAL fluid 
Table 1 Disease manifestations in patients with active sarcoidosis included in the study

\begin{tabular}{ll}
\hline Patient no. & Disease manifestation \\
\hline $1,9,11,15,20,24,27,28,29,31,32$ & Lung, LN \\
$4,6,7,13,21,22,30,34,35,37$ & Lung, LN, skin \\
$10,16,19$ & Lung, LN, eyes \\
5 & Lung, LN, eyes, salivary glands \\
\hline
\end{tabular}

LN, lymph node.

cell numbers and no clinical signs of acute disease. No patient received immunosuppressive treatment for 6 months prior to the BAL analysis.

Ten subjects were selected as controls for the BAL studies, evaluated for cough complaints without lung disease. They had normal physical examination, chest $\mathrm{X}$ rays, lung function tests and BAL cell numbers.

Written informed consent was obtained from each patient and from control subjects.

\section{Preparation of cell suspensions}

Following administration of local anaesthesia, BAL was performed and alveolar macrophages (AMs) and BAL T cells were enriched from the entire mononuclear cell suspensions as previously described. ${ }^{16} 17$ Details are reported in the online supplement.

\section{Monoclonal antibodies and cytokines}

The commercially available conjugated or unconjugated monoclonal antibodies (mAbs) used belonged to the Becton Dickinson and Pharmingen (San Diego, California, USA) series and included: CD3, CD4, CD8, CD11c, CD14, CD16, CD19, CD45R0, CD45RA, CD68 and isotype-matched controls. AntiIL23R, anti-IL-17, anti-CCR6, anti-CCL20 and anti-IFN $\gamma \mathrm{mAbs}$ were purchased from R\&D Systems Inc. (Minneapolis, Minnesota, USA).

\section{Intracellular cytokine staining}

Detection of intracellular cytokines was performed in freshly obtained lung and peripheral blood cells and in equivalent cells stimulated with $20 \mathrm{ng} / \mathrm{ml}$ phorbol-12-myristate 13-acetate (PMA) and $1 \mathrm{mM}$ ionomycin (Sigma-Aldrich, Milan, Italy). Further details are reported in the online supplement.

\section{Immunohistochemical analysis}

Lung samples from seven cases of sarcoidosis (three from active forms, two from inactive forms and two obtained from native lungs of patients requiring lung transplantation for the development of lung fibrosis), lung autoptic samples from two subjects (death due to sarcoidosis-unrelated causes) whose sarcoidosis had recovered and lymph node samples from two patients with active sarcoidosis were processed by immunohistochemistry. Details are reported in the online supplement.
RNA purification and real-time PCR for the quantification of IL-17 and ROR $\gamma \mathbf{t}$ expression by sarcoid lung cells

Total RNA was prepared from (1) purified T lymphocytes obtained from patients with sarcoid T cell alveolitis or normal $\mathrm{T}$ cells or (2) purified AMs from patients with active sarcoidosis and control subjects. Methods used for the real-time PCR are detailed in the online supplement.

\section{Statistical analysis}

Data were analysed with the assistance of the Statistical Analysis System (SAS Institute, Cary, North Carolina, USA), and statistical significance was accepted at $p<0.05$. Further details are reported in the online supplement.

\section{RESULTS}

\section{Patient characteristics}

Twenty-five subjects with high intensity alveolitis were evaluated at the onset of the disease (11 men and 14 women; mean age $51.5 \pm 9.8$ years; four smokers). Twenty-two patients required corticosteroid treatment; three patients spontaneously resolved. Eleven patients (6 men and 5 women; mean age $52.5 \pm 7.2$ years; three smokers) with previously diagnosed pulmonary sarcoidosis repeated BAL fluid analysis during their follow-up period (follow-up period average 50.7 \pm 16.6 months, range $27-78$ months). Further characteristics of patients studied are shown in table 1 . Ten subjects were selected as controls for the BAL studies ( 4 men and 6 women; mean age $44.1 \pm 8.8$ years; non-smokers)

\section{Morphological and phenotypical analyses}

Morphological and phenotypical features of cells obtained from the BAL of 36 patients with sarcoidosis and 10 control subjects are reported in table 2. All subjects with active sarcoidosis showed a high intensity $\mathrm{CD}^{+}{ }^{+}$lymphocytic alveolitis sustained by $\mathrm{CD} 45 \mathrm{RO}^{+} \mathrm{T}$ cells. The majority of these cells were equipped with the chemokine receptor CXCR3, IL-12R $\beta$ and intracytoplasmatic IFN $\gamma$ (data not shown). $\mathrm{CD}^{+}$and $\mathrm{CD}^{+} \mathrm{T}$ cell subsets and AMs detected in the BAL of patients with inactive sarcoidosis were superimposable on those observed in controls (table 2).

\section{Th17 cells in the lung and the peripheral blood of patients with sarcoidosis}

First, using a phenotypical approach, we investigated the presence of IL- $17^{+}$and IL-23R ${ }^{+}$T cells on freshly obtained pulmonary and peripheral blood cells of patients with active and inactive sarcoidosis and controls. The relative patterns are shown in figure 1.

As shown in figure $2 \mathrm{~A}$, the percentage of freshly obtained pulmonary $\mathrm{CD}^{+}{ }^{+} \mathrm{T}$ lymphocytes expressing IL-17 was much higher in patients with the active form of the disease $(8.81 \pm 2.25 \%)$ as compared with inactive sarcoidosis $\left(1.19 \pm 0.83 \%\right.$ of $\mathrm{CD}^{+} \mathrm{T}$ cells; $\mathrm{p}<0.001$ vs active disease) and

Table 2 Bronchoalveolar lavage features of patients with sarcoidosis and control subjects

\begin{tabular}{|c|c|c|c|c|c|c|c|c|c|}
\hline & \multirow{2}{*}{$\begin{array}{l}\text { Cell recovery } \\
\times 10^{3}\end{array}$} & \multicolumn{2}{|c|}{ Alveolar macrophages } & \multicolumn{2}{|c|}{ Lymphocytes } & \multicolumn{2}{|c|}{ CD4 $^{+} \mathrm{T}$ cells } & \multicolumn{2}{|c|}{ CD8 $^{+} \mathrm{T}$ cells } \\
\hline & & $\times 10^{3}$ & $\%$ & $\times 10^{3}$ & $\%$ & $\times 10^{3}$ & $\%$ & $\times 10^{3}$ & $\%$ \\
\hline Active sarcoidosis $(n=25)$ & $333 \pm 73$ & $249 \pm 58$ & $74 \pm 6$ & $82 \pm 27$ & $25 \pm 6$ & $71 \pm 25$ & $86 \pm 5$ & $11 \pm 5$ & $14 \pm 5$ \\
\hline Inactive sarcoidosis $(n=11)$ & $109 \pm 31$ & $102 \pm 27$ & $94 \pm 4$ & $5 \pm 4$ & $4 \pm 2$ & $3 \pm 2$ & $58 \pm 5$ & $2 \pm 1$ & $41 \pm 5$ \\
\hline Controls $(n=10)$ & $128 \pm 27$ & $119 \pm 27$ & $93 \pm 3$ & $9 \pm 4$ & $7 \pm 4$ & $5 \pm 2$ & $59 \pm 5$ & $4 \pm 2$ & $41 \pm 4$ \\
\hline
\end{tabular}


Figure 1 Analysis of interleukin 17 (IL17) and IL-23 expression in CD4 ${ }^{+} \mathrm{T}$ lymphocytes freshly obtained from the bronchoalveolar lavage (BAL) and the peripheral blood of patients affected by active sarcoidosis $(B, E, I, L)$, inactive sarcoidosis $(\mathrm{C}, \mathrm{F}, \mathrm{J}, \mathrm{M})$ and control subjects $(D, G, K, N)$. On the left, the physical parameter (forward scatter) and peripheral blood lymphocytes $(\mathrm{H})$ are reported. and CD4 expression of pulmonary (A)
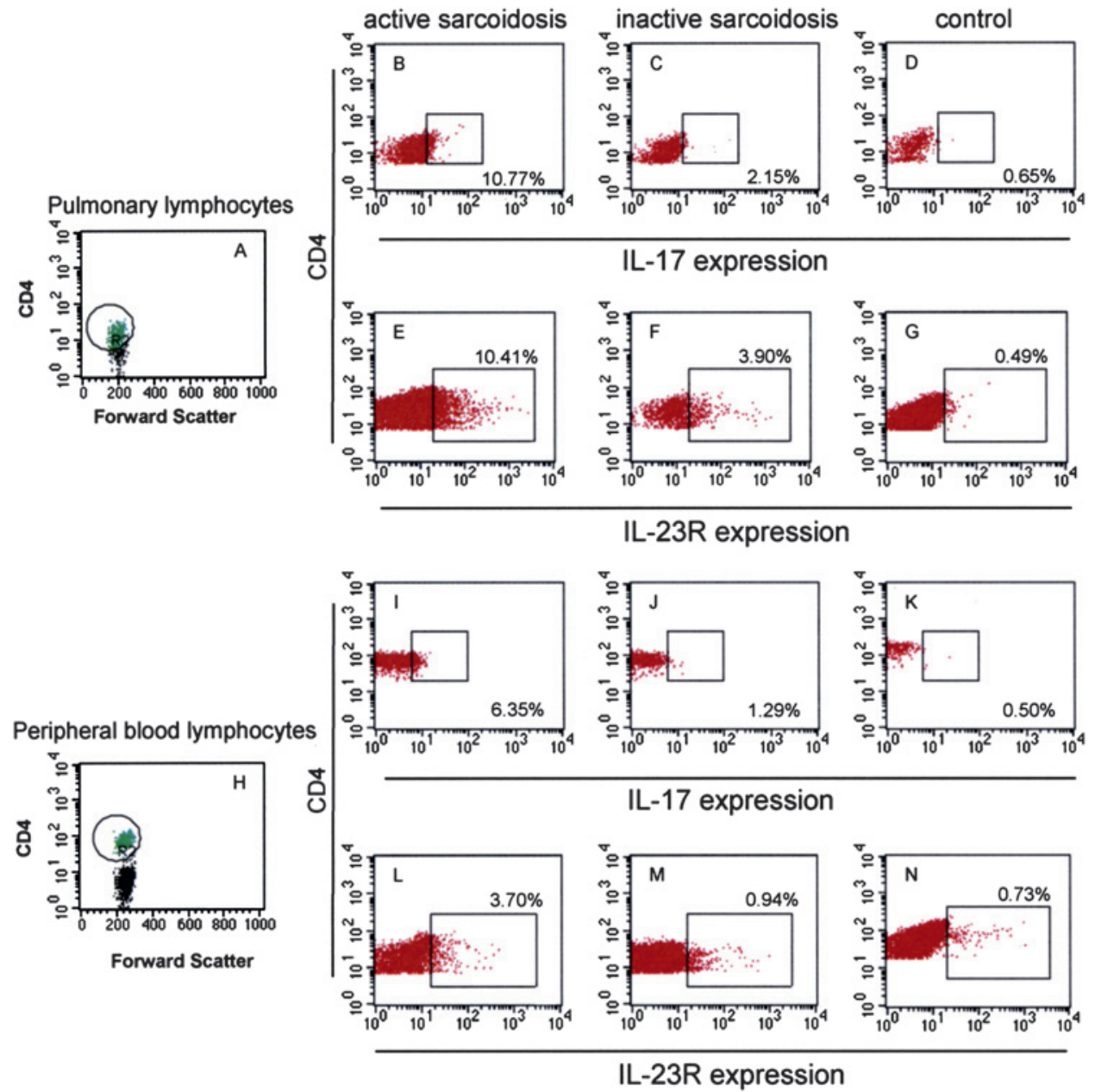

with controls $\left(0.43 \pm 0.48 \%\right.$ of $C D 4^{+} T$ lymphocytes; $p<0.001$ vs active disease; analysis of variance (ANOVA) $p<0.001$ ).

As far as IL-23R is concerned, a significantly higher percentage of lung $\mathrm{CD}^{+} \mathrm{T}$ cells obtained from patients with active sarcoidosis expressed the receptor $(9.01 \pm 2.10 \%)$ with respect to pulmonary $\mathrm{CD} 4{ }^{+} \mathrm{T}$ cells of patients with inactive sarcoidosis $(2.38 \pm 1.96 \%$; $p<0.001$ vs active disease) and controls $(0.64 \pm 0.73 \% ; p<0.001$ vs active disease; ANOVA $p<0.001$; figure $2 B$ ).

The results drawn from the peripheral blood parallel the data we obtained from the lung and confirm the multisystemic nature of the disease. In fact, the mean percentage of freshly isolated IL- $17^{+} \mathrm{T}$ cells in the $\mathrm{CD} 4^{+} \mathrm{T}$ cell subset was $4.72 \pm 2.27 \%$
Figure 2 Flow cytometry analyses of interleukin $17(\mathrm{IL}-17)^{+}(\mathrm{A})$ and IL-23R ${ }^{+}$ (B) expression evaluated in $\mathrm{CD}^{+} \mathrm{T}$ cells freshly obtained from the lung and the blood of patients affected by active sarcoidosis (black columns), inactive sarcoidosis (black and white columns) and from control subjects (white columns). (C and D) Retinoic acidrelated orphan receptor $(\mathrm{ROR}) \gamma \mathrm{t}(\mathrm{C})$ and IL-17 (D) mRNA expression in CD4 ${ }^{+}$ lung $T$ lymphocytes of patients affected by active sarcoidosis (black columns), in $\mathrm{CD}^{+}$pulmonary $\mathrm{T}$ cells of patients with inactive sarcoidosis (black and white columns) and in lymphocytes from control subjects (white columns). Data are expressed as mean $\pm S D$; ${ }^{*} \mathrm{p}<0.001$ in post hoc analyses.
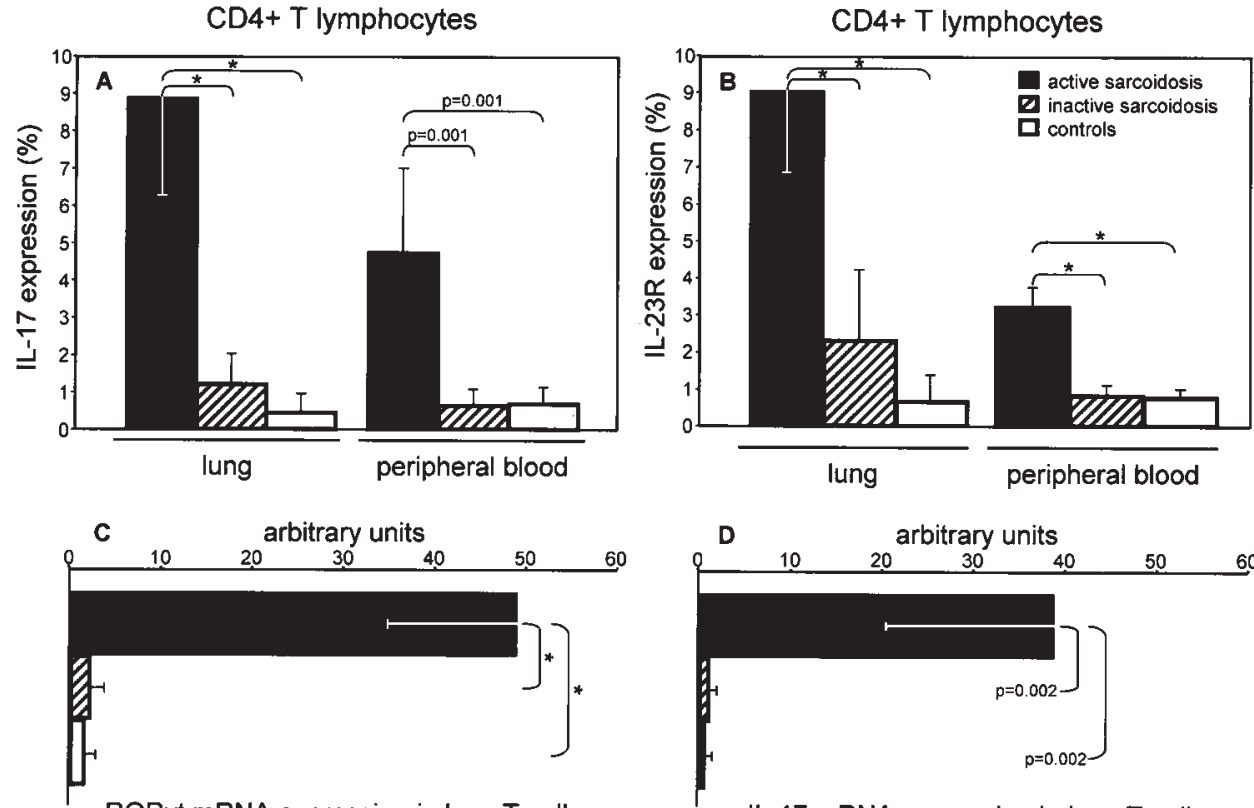

RORyt mRNA expression in lung T-cells

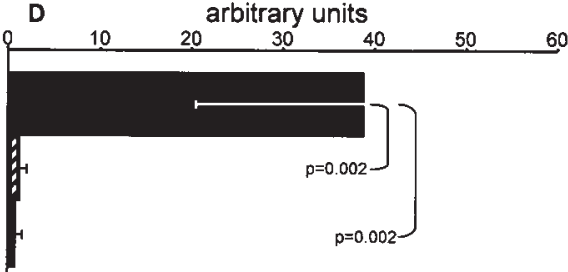

IL-17 mRNA expression in lung T-cells 
in patients with the active form of the disease, whereas the percentages of the IL- $17^{+} / \mathrm{CD} 4^{+} \mathrm{T}$ cell subset in patients with the inactive disease and in controls were $0.63 \pm 0.44 \%(p=0.001$ vs active disease) and $0.67 \pm 0.45 \%$ ( $p=0.001$ vs active disease), respectively (ANOVA $\mathrm{p}<0.001$ ) (figure $2 \mathrm{~A}$ ). The IL-23R expression was more pronounced on peripheral blood $\mathrm{CD}^{+} \mathrm{T}$ cells of patients with active sarcoidosis $(3.22 \pm 0.48 \%)$ than on $\mathrm{CD}^{+} \mathrm{T}$ lymphocytes isolated from patients with the inactive form of the disease ( $0.81 \pm 0.81 \% ; p<0.001$ vs active disease) and from the controls $(0.75 \pm 0.21 \% ; \mathrm{p}<0.001$ vs active disease; ANOVA $\mathrm{p}<0.001$; figure $2 \mathrm{~B}$ )

Stimulation of pulmonary and peripheral blood $\mathrm{CD}^{+}{ }^{+} \mathrm{T}$ cells with PMA and ionomycin induced a strong downmodulation of CD4 expression. ${ }^{18} 19$ Therefore, flow cytometric analysis was restricted to $\mathrm{CD}^{-} / \mathrm{IL}-17^{+} \mathrm{T}$ cells, that we regarded as Th17 cells. Stimulated lung T cells isolated from patients with active sarcoidosis showed an increased percentage of intracellular IL-17 (10.35 $\pm 5.84 \% ; p=0.053$ vs unstimulated cells). In parallel, the mean percentage of peripheral blood stimulated IL-17 ${ }^{+} \mathrm{T}$ cells rose to $8.43 \pm 1.65 \%$ ( $p=0.082$ vs unstimulated cells).

\section{Molecular analysis of ROR $\gamma \mathrm{t}$ and IL-17 expression by lung $\mathbf{T}$ cells}

As shown in figure 2C, real-time PCR evaluation of ROR $\gamma$ t gene expression by highly purified BAL T lymphocytes demonstrated that mRNA expression of ROR $\gamma t$ was higher in lung $\mathrm{CD}^{+} \mathrm{T}$ lymphocytes of patients with active sarcoidosis (48.80 \pm 14.07$)$ than in $\mathrm{CD}^{+} \mathrm{T}$ cells obtained from the lung of patients with
Figure 3 Analysis of interleukin 17 (IL17) and IL-23 expression in selected cell populations obtained from the bronchoalveloar lavage (alveolar macrophages) and the peripheral blood monocytes of patients affected by active sarcoidosis $(B, E, I, L)$, patients with inactive sarcoidosis $(C, F, J, M)$ and control subjects (D, G, K, N). On the left, physical parameters (side and forward scatter) of alveolar macrophages $(A)$ and peripheral blood monocytes $(\mathrm{H})$ are reported. (O and $\mathrm{P}$ ) Means of IL- $17^{+}$and IL-23R ${ }^{+}$ expression evaluated in alveolar macrophages $(0)$ and peripheral blood monocytes (P) freshly obtained from patients affected by active sarcoidosis (black columns), inactive sarcoidosis (black and white columns) and from control subjects (white columns). Data are expressed as mean $\pm S D ;{ }^{*} \mathrm{p}<0.001$ in post hoc analyses.
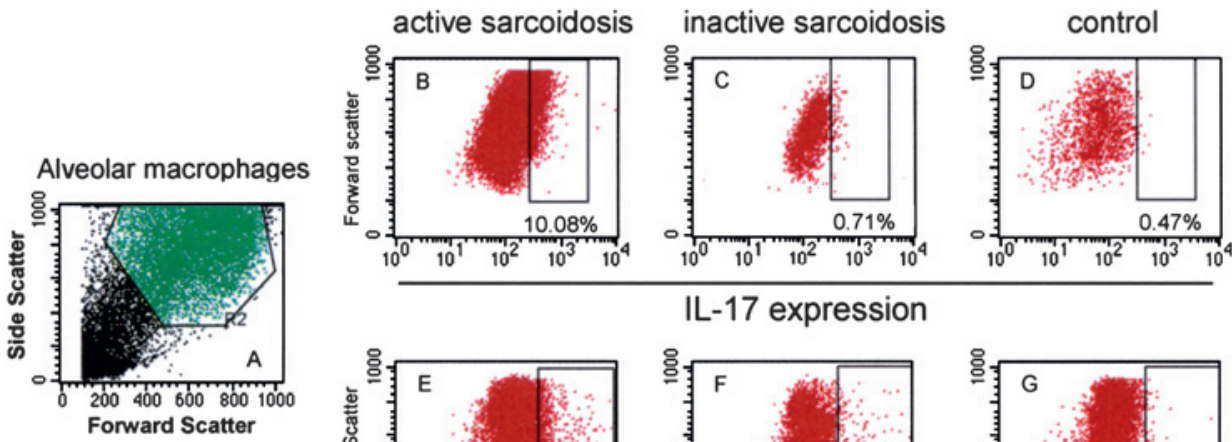

IL-17 expression
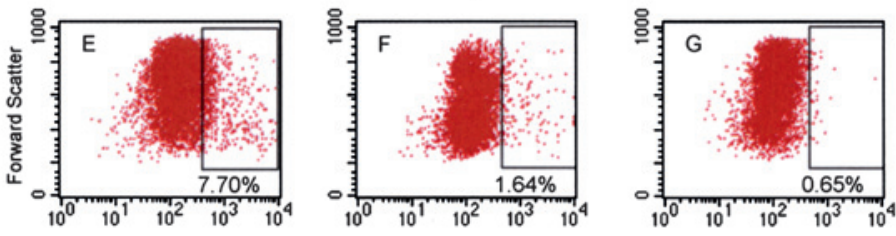

IL-23R expression
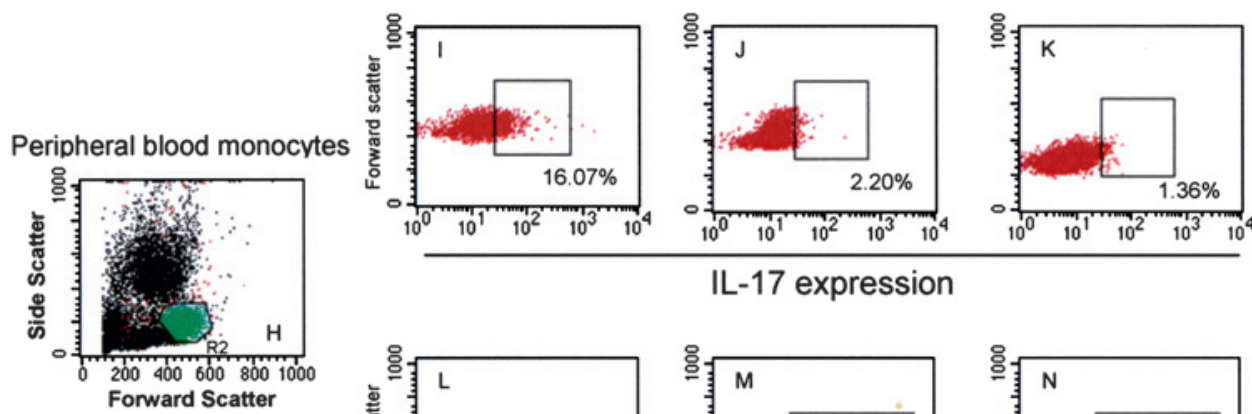

IL-17 expression
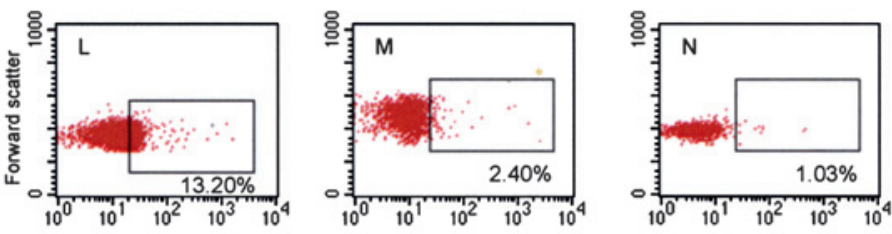

IL-23R expression

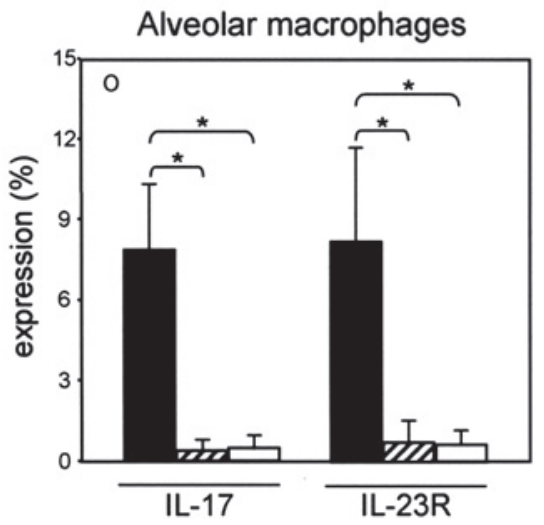

Peripheral blood monocytes

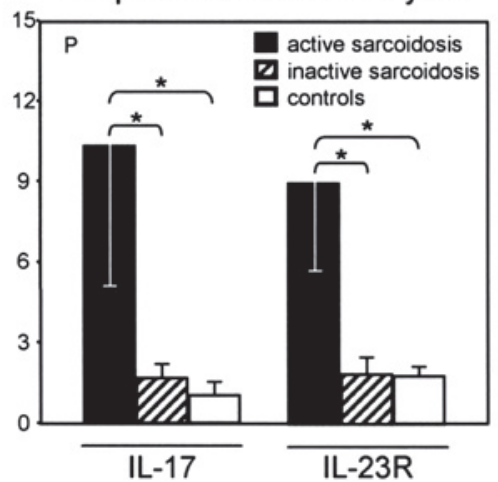


inactive disease and control subjects (inactive, 2.80 \pm 1.26 ; $\mathrm{p}<0.001$ vs active disease; controls, 1.45 $\pm 1.03 ; \mathrm{p}<0.001$ vs active disease; ANOVA $\mathrm{p}<0.001)$. Similarly, a real-time PCR evaluation of IL-17 gene expression by pulmonary $\mathrm{T}$ cells demonstrated that IL-17 mRNA was higher in lung $\mathrm{CD}^{+} \mathrm{T}$ lymphocytes of active sarcoidosis $(38.53 \pm 18.41)$ than in $\mathrm{CD}^{+}$ $T$ cells from the lung of patients with inactive disease and control subjects (inactive, $0.78 \pm 0.73 ; \mathrm{p}=0.002$ vs active disease; controls, $0.49 \pm 0.47 ; \quad p=0.002$ vs active disease; ANOVA $\mathrm{p}=0.001$; figure 2D).

\section{Sarcoid AMs express IL-17 and IL-23R}

The flow cytometric analysis of freshly isolated AMs obtained from the BAL of the lungs of patients with active sarcoidosis showed the intracellular expression of IL-17 (7.88 $\pm 2.40 \%)$ and the surface presence of IL-23R $(8.13 \pm 3.47 \%)$. In contrast, a very low expression of IL-17 and IL-23R was detected on the AMs from patients with inactive sarcoidosis (IL-17, $0.39 \pm 0.34 \%$; $\mathrm{p}<0.001$ vs active disease; IL-23R, $0.74 \pm 0.80 \% ; \mathrm{p}<0.001$ vs active disease) and from controls (IL-17, $0.48 \pm 0.46 \% ; \mathrm{p}<0.001$ vs active disease; IL-23R, $0.64 \pm 0.56 \% ; \mathrm{p}<0.001$ vs active disease; ANOVA $\mathrm{p}<0.001$ for both; figure $3 \mathrm{~A}-\mathrm{G}, \mathrm{O})$.
Interestingly, peripheral monocytes of patients with active sarcoidosis showed a significantly increased expression of IL-17 $(10.33 \pm 5.26 \%)$ and IL-23R $(8.94 \pm 3.35 \%)$ in comparison with monocytes obtained from patients with inactive sarcoidosis (IL$17,1.68 \pm 0.51 \% ; p<0.001$ vs active disease; IL-23R, $1.86 \pm 0.63 \%$; $\mathrm{p}<0.001$ vs active disease) and controls (IL-17, $1.03 \pm 0.40 \%$; $\mathrm{p}<0.001$ vs active disease; IL-23R, $1.78 \pm 0.36 \% ; \mathrm{p}<0.001$ vs active disease; ANOVA $\mathrm{p}<0.001$ for both; figure $3 \mathrm{H}-\mathrm{N}, \mathrm{P}$ ).

\section{Immunohistochemical analysis of IL-23R and IL-17 expression}

Immunohistochemical analysis confirmed the expression of IL23R and IL-17 by sarcoid lung $\mathrm{T}$ cells infiltrating surgical pulmonary biopsies obtained from four patients with active sarcoidosis (figure 4A,B). When the cell sources of IL-17 in sarcoid tissue was investigated, we showed that the cytokine was preferentially expressed by macrophage multinucleated giant cells and T cells localised inside the granuloma. We identified IL-17 ${ }^{+} \mathrm{T}$ cells infiltrating lymph node granulomas of patients with active sarcoidosis (figure 4E,1-2), thus documenting the presence of Th17 cells at the extrapulmonary active sites of the disease. Immunohistochemical analysis of native lungs obtained from three patients with refractory sarcoidosis
Figure 4 Immunohistochemistry for interleukin 17 (IL-17) and IL-23R expression in three representative patients with active $(A, B, E)$ and inactive $(C, D)$ sarcoidosis. (A and $B$ ) IL17 and IL-23R are expressed at high intensity by macrophagic, both epitheliod and multinucleated, cells and lymphocytes infiltrating the lung biopsy of the patient with active sarcoidosis. $(a, b)$ Serum isotype controls with haematoxylin counterstain. (C and D) In the lung specimen obtained from a patient in the inactive phase of the disease, pulmonary $T$ cells were mainly non-reactive for IL-17 and IL-23R; a weak immunostaining was only seen in some epitheliod macrophagic cells. Note the negative staining in multinucleated cells (arrows). (E) IL-17 is expressed by $T$ cells infiltrating the lymph node biopsy of the patient with active sarcoidosis. $(1,2)$ Enlargement of areas in E. Original magnification $\times 200$.

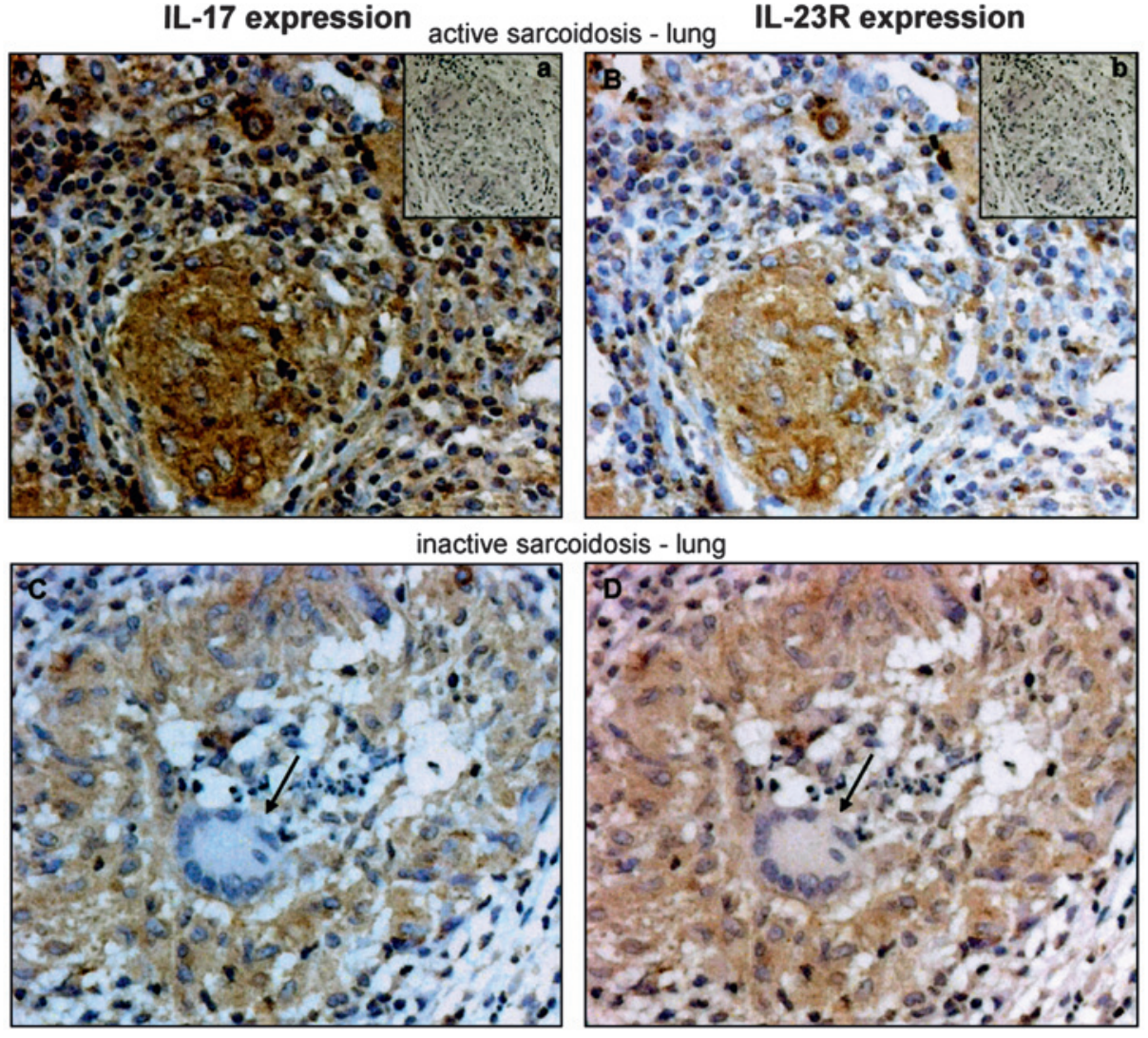

\section{IL-17 expression}
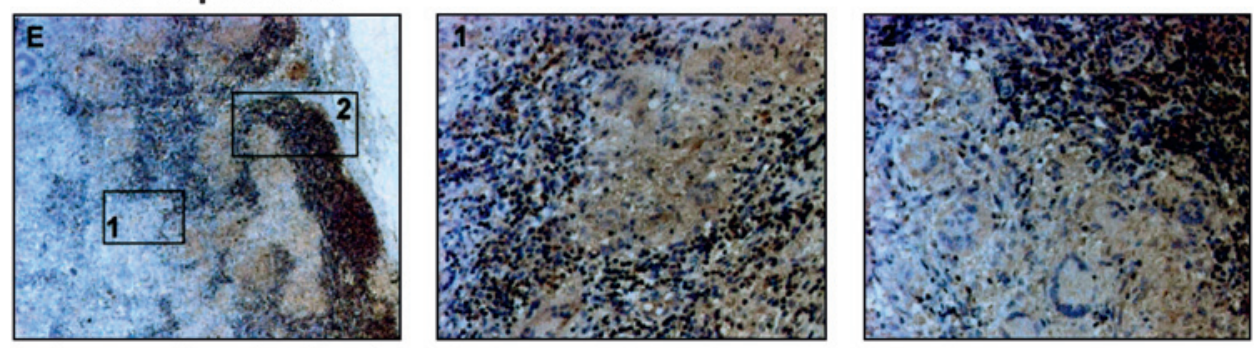

active sarcoidos - lymph node 
Figure 5 Immunohistochemistry for lung interleukin 17 (IL-17) expression in a representative patient with sarcoidosis relapse $(A)$ and in lung autoptic samples from two subjects (death due to sarcoidosis-unrelated causes) whose sarcoidosis had recovered $(B, C, D, E)$. (A) IL-17 is expressed at high intensity by macrophagic cells and lymphocytes infiltrating the lung biopsy of the relapsed patient. (B, $C, D$ and $E)$ In the lung autoptic specimens, pulmonary $\mathrm{T}$ cells were non-reactive for IL-17 antibody.

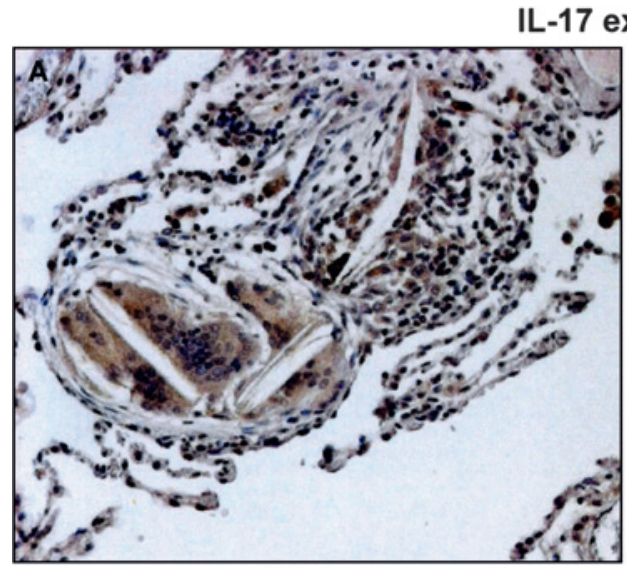

sarcoidosis relapse
IL-17 expression

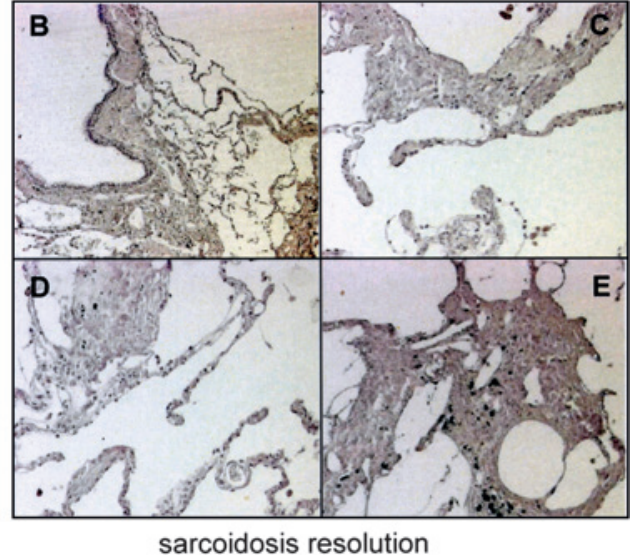

and pulmonary fibrosis who underwent lung allograft transplantation showed that in the fibrotic phase of the disease, lung T cells were mainly non-reactive for IL-23R and IL-17, and AMs were not stained with anti-IL-17 mAb (figure 4C,D).

To investigate the role of Th17 cells in different phases of the disease, we analysed surgical pulmonary biopsies obtained from two patients with sarcoidosis relapse and from two subjects whose sarcoidosis underwent resolution (figure 5). Interestingly, we identified IL-17 ${ }^{+} \mathrm{T}$ cells only in the relapsed patient, suggesting the critical role of Th17 cells in sarcoidosis progression.

\section{Pulmonary Th17 cells expressed a functional CCR6 receptor}

Th17 cells are characterised by the expression of CCR6, the receptor of the chemokine CCL20. ${ }^{13}$ By flow cytometric analysis, we showed that this receptor is highly expressed by Th17 cells of patients with sarcoidosis $\left(79.33 \pm 11.19 \%\right.$ of $\mathrm{IL}-17^{+} /$ $\mathrm{CD}^{+}{ }^{+} \mathrm{T}$ cells) (figure 6). In a previous work, ${ }^{8}$ we demonstrated the involvement of the CCR6/CCL20 axis in the lung microenvironment of patients with sarcoidosis. Herein, we confirmed that sarcoid lung T lymphocytes bear CCR6 (45.6 $\pm 7.8 \%$ of $\mathrm{CD}^{+}{ }^{+} \mathrm{T}$ cells; $52.3 \pm 7.1 \%$ of $\mathrm{CCR} 6^{+} \mathrm{CD} 4^{+} \mathrm{T}$ cells were CXCR3 negative) and migrate in the presence of CCL20 (74.8 $\pm 8.5 \mathrm{vs}$ $7.6 \pm 2.8$ migrating BAL lymphocytes/high-powered field, in the presence and absence of CCL20, respectively; $p<0.001)$. It is noteworthy that we showed that sarcoid macrophages release CCL20 and that detectable levels of CCL20 protein can be demonstrated in the BAL fluid components. ${ }^{8}$
Lung CD4+ T cells

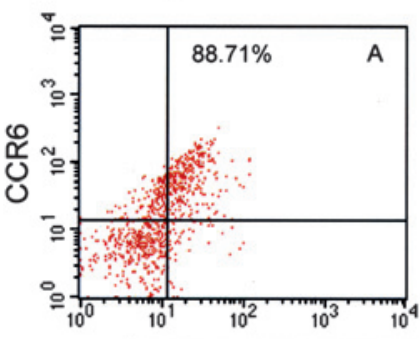

Peripheral blood CD4+ T cells

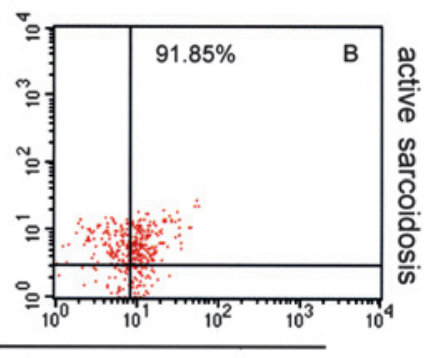

IL-17
Figure 6 Flow cytometry analysis of the expression of $\mathrm{CCR6}^{+}$on interleukin $17(\mathrm{IL}-17)^{+} / \mathrm{CD}^{+} \mathrm{T}$ cells in the lung $(\mathrm{A})$ and the blood $(\mathrm{B})$ of a representative patient with active sarcoidosis.

\section{DISCUSSION}

In this report we have provided evidence that Th17 cells infiltrate sarcoid lung, localising around and inside the granuloma, at the sites of disease activity, not only in the early phase, but also in the progression towards the fibrotic phase of the disease.

In patients with sarcoidosis, the pulmonary microenvironment is characterised by a well-known highly polarised Th1 profile. ${ }^{620}$ Despite the in vitro inhibition of Th17 development by Th1-derived IFN $\gamma^{21}{ }^{22}$ the presence in vivo of a Th1/Th17 population has been extensively demonstrated in different pathological conditions characterised by an exaggerated inflammatory response, including psoriasis, ${ }^{13}$ rheumatoid arthritis, ${ }^{23}$ Crohn's disease, ${ }^{24}$ hypersensitivity pneumonitis ${ }^{25}$ and tuberculosis. ${ }^{26}$ We detected high levels of IL- $17^{+} / \mathrm{CD} 4^{+} \mathrm{T}$ lymphocytes among cells retrieved from the BAL of patients with sarcoidosis. In particular, patients with a marked alveolitis showed the highest amounts of Th17 cells, both in the lung and in the peripheral blood, suggesting an overall increase of this subset, spreading from the periphery to the sites of active disease. In a previous report, Meloni et $a^{27}$ assessed the frequency of Th1, Th2 and Th17 lymphocytes in the BAL of patients with interstitial lung diseases, including sarcoidosis (15 cases), describing no variation of Th17 clones in the patients compared with controls. The different technical approaches (an IL17Elispot and a different stimulation of $\mathrm{T}$ cells) may explain the contradictory results they obtained. In addition, the reported absence of any increase in the basal frequency of lung IFN $\gamma$ producing cells in the patients with sarcoidosis included in this study is a feature conflicting with the classical, active Th1 pulmonary microenvironment.

The evidence that Th17 cells are increased in the lung and the peripheral blood of patients with active sarcoidosis supports the multisystem nature of the disease but raises the issue of the diminished cellular immune response in the blood of patients with sarcoidosis. Regulatory $T$ lymphocytes (Tregs) of patients with sarcoidosis deeply affect the concomitant presence of an intense immune response in the affected organs and a reduced/ suppressed antigen immune response in the periphery. Actually, the interactions between Tregs and Th17 cells are not completly understood. Intriguingly, recent data demonstrated the plasticity/instability of Tregs, mainly in the presence of some proinflammatory cytokines, such as IL-6, that converted T cell receptor (TCR)-stimulated Tregs into Th17 lymphocytes in vitro. $^{28}$

Sarcoid AMs produce elevated levels of IL-17. Recent studies showed the relevant role of monocytes/macrophages in the 
promotion of the Th17 response. In fact, activated monocytes obtained from the synovial fluid of patients with rheumatoid arthritis specifically induce the Th17 response via cell contact signals and IL-1 $\beta /$ TNF $\alpha$ cytokines. ${ }^{29}$ Our data favour the hypothesis that a Th17 response may be driven by AMs since IL-1 $\beta$ - and TNF $\alpha$-producing AMs are widely detectable in sarcoid lung.

$\mathrm{IL}-17^{+} / \mathrm{CD}^{+} \mathrm{T}$ cells were further characterised for the expression of IL-23R, the master gene ROR $\gamma$ t and the CCR6 receptor, a recently recognised Th17 marker. ${ }^{13}$ IL-23R binds IL23, a cytokine involved in human Th17 cell differentiation. ${ }^{30}$ The overexpression of this molecule on $\mathrm{CD}^{+}{ }^{+} \mathrm{T}$ cells parallels the increase in $\mathrm{IL}-17^{+} / \mathrm{CD} 4^{+} \mathrm{T}$ lymphocytes, both in the lung and in the blood of patients with active sarcoidosis. ROR $\gamma$ t and CCR6 are two strictly linked molecules: ROR $\gamma$ t directs Th17 cell differentiation and specifically controls the differentiation of $\mathrm{CD}^{+}{ }^{+} \mathrm{T}$ cells towards CCR ${ }^{+}$Th17 cells, as demonstrated by $\mathrm{ROR} \gamma \mathrm{t}$ transduction experiments in $\mathrm{CCR} 6^{-} / \mathrm{CD} 4^{+} \mathrm{T}$ cells. ${ }^{23}$ The pulmonary and peripheral Th17 cells of our patients overexpressed the ROR $\gamma \mathrm{t}$ mRNA and showed a strong positivity for CCR6 protein. Actually, CCL20 is the only chemokine produced and released by Th17 cells.

In a previous work, ${ }^{8}$ we demonstrated that sarcoid macrophages and epithelioid cells, forming the central core of the sarcoid granuloma, express and release detectable amounts of CCL20. According to the present results, we support the hypothesis that these cells are Th17 lymphocytes since they express a fully functional CCR6 receptor whose interactions with the specific ligand CCL20 regulate Th17 cell trafficking: airway epithelial cells and AMs recruit Th17 cells into the lung through CCL20 release, which is enhanced by proinflammatory cytokines such as IL-1 $\beta$ and TNF $\alpha^{7}$ Probably, Th17 cells favour disease progression, as our preliminary results on patients with sarcoidosis evolving towards fibrosis (figure 5) seem to point out. The involvement of IL-17A in the development of fibrosis was recently demonstrated in a murine model of bleomycin-induced pulmonary fibrosis. ${ }^{31}$ IL-17A was detected both in the early phase of inflammation, together with IFN $\gamma$ (a Th1/Th17 response), and at later times, with IFN $\gamma$ and IL-13 (a mixed Th1/ Th17/Th2 response). In addition, the experiments conducted with C57BL/6 IL-17A ${ }^{-1-}$ mice confirmed the role of IL-17 in driving the development/progress of fibrosis, facilitated by IFN $\gamma$ and IL-12/23p40, and in association with transforming growth factor $\beta$ (TGF $\beta$ ). In this context, IL-17 may represent a common denominator in the events leading to fibrosis development in interstitial lung diseases.

In conclusion, our data highlight the presence of Th17 cells in the lung and the blood of patients with sarcoidosis, particularly in those patients with the active form of the disease, suggesting a role for the Th17 subset in sarcoidosis progression. Further studies are needed to better understand the role of Th17 cells in the various stages of the disease and to validate the possibility of a treatment based on Th17 and/or IL-17 neutralisation.

Acknowledgements The authors wish to thank Mr Luca Braghetto for technical assistance in the preparation of lung biopsies for immunohistochemical analysis.

Funding MF has received a grant from Padua University, Progetto di Ateneo CPDA063349/06. GS (PRIN 2007) and CA (PRIN 2009) have received grants from the Italian Ministry of University, Research, and Education, Rome (Italy).

Competing interests None.

Ethics approval This study was conducted with the approval of the Padova Hospital Ethics Committee.

Provenance and peer review Not commissioned; externally peer reviewed.

\section{REFERENCES}

1. Baughman RP, Lower EE, du Bois RM. Sarcoidosis. Lancet 2003;361:1111-18.

2. Semenzato G, Adami F, Maschio N, et al. Immune mechanisms in interstitial lung diseases. Allergy 2000;55:1103-20.

3. Agostini C, Trentin L, Perin A, et al. Regulation of alveolar macrophage-T cell interactions during Th1-type sarcoid inflammatory process. Am J Physiol 1999;277: L240-50.

4. Agostini C, Trentin L, Facco M, et al. Role of IL-15, IL-2, and their receptors in the development of $\mathrm{T}$ cell alveolitis in pulmonary sarcoidosis. J Immunol 1996;157:910-18.

5. Agostini C, Cassatella M, Zambello R, et al. Involvement of the IP-10 chemokine in sarcoid granulomatous reactions. J Immunol 1998;161:6413-20.

6. Agostini C, Cabrelle A, Calabrese F, et al. Role for CXCR6 and its ligand CXCL16 in the pathogenesis of T-cell alveolitis in sarcoidosis. Am J Respir Crit Care Med 2005;172:1290-8.

7. Vasakova M, Sterclova M, Kolesar L, et al. Bronchoalveolar lavage fluid cellular characteristics, functional parameters and cytokine and chemokine levels in interstitial lung diseases. Scand J Immunol 2009;69:268-74.

8. Facco M, Baesso I, Miorin M, et al. Expression and role of CCR6/CCL20 chemokine axis in pulmonary sarcoidosis. J Leukoc Biol 2007;82:946-55.

9. Annunziato F, Cosmi L, Santarlasci V, et al. Phenotypic and functional features of human Th17 cells. J Exp Med 2007:204:1849-61.

10. Ivanov II, McKenzie BS, Zhou L, et al. The orphan nuclear receptor RORgammat directs the differentiation program of proinflammatory $\mathrm{L}-17+\mathrm{T}$ helper cells. Cell 2006; 126:1121-33

11. Manel N, Unutmaz D, Littman DR. The differentiation of human $\mathrm{T}(\mathrm{H})-17$ cells requires transforming growth factor-beta and induction of the nuclear receptor RORgammat. Nat Immunol 2008;9:641-9

12. Romagnani S, Maggi E, Liotta F, et al. Properties and origin of human Th17 cells Mol Immunol 2009:47:3-7.

13. Kryczek I, Bruce AT, Gudjonsson JE, et al. Induction of IL-17+ T cell trafficking and development by IFN-gamma: mechanism and pathological relevance in psoriasis. J Immunol 2008;181:4733-41.

14. Tesmer LA, Lundy SK, Sarkar S, et al. Th17 cells in human disease. Immunol Rev 2008;223:87.

15. Kleinschek MA, Boniface K, Sadekova S, et al. Circulating and gut-resident human Th17 cells express CD161 and promote intestinal inflammation. J Exp Med 2009:206:525-34

16. Agostini C, Calabrese F, Poletti V, et al. CXCR3/CXCL10 interactions in the development of hypersensitivity pneumonitis. Respir Res 2005;6:20

17. Agostini C. Facco M Siviero M et al. CXC chemokines IP-10 and mig expression and direct migration of pulmonary CD8 $+/ C X C R 3+T$ cells in the lungs of patients with HIV infection and T-cell alveolitis. Am J Respir Crit Care Med 2000:162:1466-73

18. Koga C, Kabashima K, Shiraishi N, et al. Possible pathogenic role of Th17 cells for atopic dermatitis. J Invest Dermatol 2008;128:2625-30.

19. Yang J, Chu Y, Yang X, et al. Th17 and natural Treg cell population dynamics in systemic lupus erythematosus. Arthritis Rheum 2009;60:1472-83.

20. Miyara M, Amoura Z, Parizot $\mathrm{C}$, et al. The immune paradox of sarcoidosis and regulatory T cells. J Exp Med 2006;203:359-70

21. Veldhoen $\mathbf{M}$, Hocking RJ, Atkins CJ, et al. TGFbeta in the context of an inflammatory cytokine milieu supports de novo differentiation of IL-17-producing $\mathrm{T}$ cells. Immunity 2006;24:179-89.

22. Bettelli E, Carrier $\mathrm{Y}, \mathrm{Gao} \mathrm{W}$, et al. Reciprocal developmental pathways for the generation of pathogenic effector $\mathrm{TH} 17$ and regulatory $\mathrm{T}$ cells. Nature 2006:441:235-8

23. Hirota $\mathbf{K}$, Yoshitomi $\mathrm{H}$, Hashimoto $\mathrm{M}$, et al. Preferential recruitment of CCR6-expressing Th17 cells to inflamed joints via CCL20 in rheumatoid arthritis and its animal model. J Exp Med 2007;204:2803-12.

24. Brand S. Crohn's disease: Th1, Th17 or both? The change of a paradigm: new immunological and genetic insights implicate Th17 cells in the pathogenesis of Crohn's disease. Gut 2009;58:1152-67.

25. Joshi AD, Fong DJ, Oak SR, et al. Interleukin-17-mediated immunopathogenesis in experimental hypersensitivity pneumonitis. Am J Respir Crit Care Med 2009;179:705-16.

26. Babu S, Bhat SQ, Kumar NP, et al. Human type 1 and 17 responses in latent tuberculosis are modulated by coincident filarial infection through cytotoxic T lymphocyte antigen-4 and programmed death-1. J Infect Dis 2009; 200:288-98

27. Meloni F, Solari N, Cavagna L, et al. Frequency of Th1, Th2 and Th17 producing T lymphocytes in bronchoalveolar lavage of patients with systemic sclerosis. Clin Exp Rheumatol 2009;27:765-72.

28. Zheng SG, Wang J, Horwitz DA. Cutting edge: Foxp3 + CD4 + CD25+ regulatory T cells induced by IL-2 and TGF-beta are resistant to Th17 conversion by IL-6. $\mathrm{J}$ Immunol 2008;180:7112-16.

29. Evans HG, Gullick NJ, Kelly S, et al. In vivo activated monocytes from the site of inflammation in humans specifically promote Th17 responses. Proc Natl Acad Sci USA 2009;106:6232-7.

30. Wilson NJ, Boniface K, Chan JR, et al. Development, cytokine profile and function of human interleukin 17-producing helper T cells. Nat Immunol 2007:8:950-7.

31. Wilson MS, Madala SK, Ramalingam TR, et al. Bleomycin and IL-1beta-mediated pulmonary fibrosis is IL-17A dependent. J Exp Med 2010:207:535-52. 